\title{
Expression of tropomyosin 2 gene isoforms in human breast cancer cell lines
}

\author{
SYAMALIMA DUBE, ANISH THOMAS, LYNN ABBOTT, PATRICIA BENZ, \\ CHARLES MITSCHOW, DIPAK K. DUBE and BERNARD J. POIESZ
}

Division of Hematology/Oncology, Department of Medicine, Upstate Medical University, Syracuse, NY 13210, USA

Received October 8, 2015; Accepted November 12, 2015

DOI: 10.3892/or.2016.4732

\begin{abstract}
In humans, four tropomyosin genes (TPM1, TPM2, TPM3, and TPM4) are known to produce a multitude of isoforms via alternate splicing and/or using alternate promoters. Expression of tropomyosin has been shown to be modulated at both the transcription and the translational levels. Tropomyosins are known to make up some of the stress fibers of human epithelial cells and differences in their expression has been demonstrated in malignant breast epithelial cell lines compared to 'normal' breast cell lines. We have recently reported the expression of four novel TPM1 isoforms (TPM1 $\lambda$, TPM1 $\mu$, TPM1 $v$, and TPM1 $\xi$ ) from human malignant tumor breast cell lines that are not expressed in adult and fetal cardiac tissue. Also, we evaluated their expression in relation to the stress fiber formation. In this study, nine malignant breast epithelial cell lines and three 'normal' breast cell lines were examined for stress fiber formation and expression of tropomyosin 2 (TPM2) isoform-specific RNAs and proteins. Stress fiber formation was assessed by immunofluorescence using Leica AF6000 Deconvolution microscope. Stress fiber formation was strong $(++++)$ in the 'normal' cell lines and varied among the malignant cell lines (negative to +++ ). No new TPM 2 gene RNA isoforms were identified, and TPM2 $\beta$ was the most frequently expressed TPM2 RNA and protein isoform. Stress fiber formation positively correlated with TPM $2 \beta$ RNA or protein expression at high, statistically

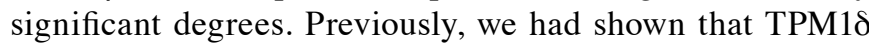
and TPM1 $\lambda$ positively and inversely, respectively, correlated with stress fiber formation. The most powerful predictor of stress fiber formation was the combination of TPM $2 \beta$ RNA, TPM1 $\delta$ RNA, and the inverse of TPM1 $\lambda$ RNA expression. Our results suggest that the increased expression of TPM1 $\lambda$ and the decreased expression of TPM1 $1 \delta$ RNA and TPM $2 \beta$ may lead to
\end{abstract}

Correspondence to: Dr Bernard J. Poiesz, Division of Hematology/ Oncology, Department of Medicine, Upstate Medical University, Syracuse, NY 13210, USA

E-mail: poieszb@upstate.edu

Key words: TPM2 isoforms, RT-PCR, western blot analysis, stress fiber, immunofluorescence decreased stress fiber formation and malignant transformation in human breast epithelial cells.

\section{Introduction}

There are four relatively homologous human tropomyosin (TPM) genes which exhibit varying degrees of expression in human tissues (1-6). Expression has been shown to be modulated at the transcriptional and translational level $(7,8)$. Multiple molecular TPM isoforms have been identified, which are the results of alternative promoters or alternative splicing.

Tropomyosin proteins have been shown to make up some of the stress fibers of human epithelial cells, and differences in their expression have been demonstrated in malignant breast epithelial cell lines and tissues compared to 'normal' breast cell lines and tissues (1,3,9-15). Much of this work has focused on TPM2 $\beta$ (also known as TM1) and TPMI $\gamma$ and $\delta$. Recently, we have published on the expression of four novel TPM1 gene RNA isoforms $(\lambda, \mu, v$ and $\xi)$ in human breast cell lines (16). TPM1 $\lambda$ was the most frequent novel isoform expressed in the malignant breast cell lines, and it was not found in a normal breast epithelial cell line. Its expression was inversely correlated in a statistically significant degree with stress fiber formation in these human breast epithelial cell lines. Also, the expression of TPM1 $\delta$, but not TPM $1 \gamma$, was positively correlated with stress fiber formation. We have also published on the expression of novel TPM 2 gene isoforms (TPM $2 \delta-\eta)$ in human cardiac tissues (17). Given the above observations, we decided to re-examine TPM2 isoform expression in human breast cancer cell lines. Hence, using a series of primer pairs and probes and four different exon-specific human tropomyosin protein antibodies, we examined TPM 2 gene RNA and protein isoform expression in nine malignant and three benign human breast cell lines. Two human B-lymphocytic cell lines from two of the same breast cancer patients, and human adult and fetal cardiac and adult skeletal muscle were used as controls. The cell lines were also examined for stress fiber formation.

\section{Materials and methods}

RNA of human adult and fetal cardiac tissue was obtained from Zyagen (San Diego, CA, USA); similar protein samples were obtained from Imgenex (San Diego, CA, USA). Human skeletal muscle proteins were obtained from Imgenex. The 
Table I. Nucleotide sequences of the primer pairs and probes used to amplify and detect TPM2 RNAs.

Primer/probe

Nucleotide sequences

GAPDH.P1(+):

GAPDH. P2(-):

GAPDH. Probe:

TPM2. Exon 1a(+):

TPM2. Exon 9a(-):

TPM2. Exon 9d(-):

TPM2. Probe Exon 5(+):
5'-GTTTACATGTTCCAATATGATTCCAC-3'

5'-TCATATTTGGCAGGTTTTCTAGA-3'

5'-GTGGAGTCCACTGGCGTCTT-3'

5'-ATGGACGCCATCAAGAAGAA-3'

5'-CTTGTACTTCATCTTCTGGGCAT-3'

5'-TGGGGCTGGCCCTCACAGGTT-3'

5'-AGAGGGCTGAGGTGGCCGAGAGCCG-3' non-malignant human breast cell lines MCF-10A, MCF-12A and MCF-184B5, the normal human B-cell lines HCC-1143 (BL) and HCC-187 (BL), and the malignant human breast cancer cell lines HCC-1143, HCC-1187, BT-474, mDAMB-157, HCC-1806, HCC-1419, mDAMB-453, mDAMB-468, and MCF7 were obtained from American Type Culture Collection (ATCC; Manassas, VA, USA).

Cell culture. MCF7 cells were cultured in Eagle's minimum essential medium (ATCC) with $0.01 \mathrm{mg} / \mathrm{ml}$ bovine insulin (Sigma-Aldrich, St. Louis, MO, USA) and $10 \%$ fetal bovine serum (FBS) at $37^{\circ} \mathrm{C}$ in $5 \% \mathrm{CO}_{2}$. MCF-10A cells and $184 \mathrm{~B} 5$ cells were cultured in Clonetics Mammary Epithelial Basal medium (Lonza, Rochester, NY, USA) with $100 \mathrm{ng} / \mathrm{ml}$ (MCF$10 \mathrm{~A})$ or $1 \mathrm{ng} / \mathrm{ml}(184 \mathrm{~B} 5)$ cholera toxin (Sigma-Aldrich) at $37^{\circ} \mathrm{C}$ in $5 \% \mathrm{CO}_{2}$. MDA-MB-468, MDA-MB-453, and MDA-MB157 cells were cultured in Leibovitz's L-15 medium with $10 \%$ $\mathrm{FBS}$ at $37^{\circ} \mathrm{C}$ in atmospheric air.

Cells were cultured in Corning ${ }^{\circledR}$ T-75 flasks until $60-80 \%$ confluent and were then trypsinized, washed and $2-3 \times 10^{5}$ cells were resuspended in $3 \mathrm{ml}$ of the appropriate culture medium and plated in MatTek Glass Bottom Culture dishes (day 0). Plates were incubated at $37^{\circ} \mathrm{C}\left(5 \% \mathrm{CO}_{2}\right.$ or atmospheric air) for 2 days and paraformaldehyde fixed for staining (day 2). The cell lines were similarly cultured and cells were harvested for RNA and protein extraction.

Immunofluorescence. Cells were fixed in 3\% paraformaldehyde in phosphate-buffered saline (PBS) for $15 \mathrm{~min}$ at room temperature. The fixed cells were rinsed twice with standard salt solution $(0.1 \mathrm{M} \mathrm{KCl}), 0.01 \mathrm{M} \mathrm{MgCl}_{2}, 0.01 \mathrm{M}$ phosphate buffer, $\mathrm{pH}$ 7.0) and permeablilized with $0.1 \%$ IGEPAL (Sigma-Aldrich) in standard salt for $10 \mathrm{~min}$ at room temperature. The free aldehyde groups in IGEPAL-treated cultured cells were removed by quenching with $50 \mathrm{mM} \mathrm{NH}_{4} \mathrm{Cl}$ for $5 \mathrm{~min}$. Cells were then washed with salt solution for $2 \mathrm{~min}$. The rinsing process was repeated 3 times and the cells were blocked with $1 \%$ BSA in standard salt for $1 \mathrm{~h}$. The blocked cells were rinsed for $2 \mathrm{~min}$ with standard salt. The cells were then incubated $2 \mathrm{~h}$ at room temperature with primary anti-tropomyosin antibody TM311 (1:1,000 dilution; Abcam, Cambridge, MA, USA). Cells were washed 8 times with standard salt and washed cells were incubated with Alexa Fluor 488 secondary antibody [donkey anti-mouse IgG H\&L (Abcam)] in 1:20 dilution for $1 \mathrm{~h}$ at $37^{\circ} \mathrm{C}$. The cells were washed 8 times each for $3 \mathrm{~min}$ with standard salt. The cells were next stained with Alexa
Fluor 594 phalloidin (diluted stock 1:25; Life Technologies, Grand Island, NY, USA) for $30 \mathrm{~min}$ at room temperature, rinsed with standard salt (8 times) and distilled water for 5 min $\times 3$. Nuclei were then stained with DNA-binding DAPI [(4',6-diamidino-2-phenylindole); Sigma-Aldrich] for $30 \mathrm{~min}$ and rinsed 3 times with standard salt. Cells were mounted in Mowiol (Sigma-Aldrich) with $2.5 \% \mathrm{G}$ n-propyl gallate (Sigma-Aldrich). The specimens were sequentially activated with different wavelengths of light and images were collected with a Leica AF6000 Deconvolution microscope. The images were then merged to make a composite picture.

RNA and protein analysis. Total cellular RNA and protein were prepared from the samples as previously described (18). For RT-PCR, $0.5 \mu \mathrm{g}$ of RNA in a total volume of $40 \mathrm{ml}$ was used to synthesize cDNA with SuperScript ${ }^{\circledR}$ II (Life Sciences) and oligo-dT primers following the manufacturer's specifications. For each PCR, $3 \mu \mathrm{l}$ of cDNA was used. GAPDH housekeeping gene RNA and TPM2 RNA were amplified as previously described (18). Amplified cDNA was detected using Southern blot hybridization, as previously described (19). Qualitative relative amounts of signal intensity were scored as negative up to +++++ . The primer pairs and probes utilized are listed in Table I.

The above primer pair/probe groups divided the known TPM2 isoforms into two sets (Fig. 1). However, the generic probe utilized did not further distinguish among the potential different isoforms. In order to identify and quantify individual isoforms, the above amplified DNAs were cloned and sequenced as previously described (20). Fourteen clones were examined for each cell line and each positive primer pair set. The Southern signal intensity obtained in the original RNA-PCR assay was then divided among the different isoforms according to their percentage of the 14 sequenced colonies.

Protein from $10^{6}$ cells of each cell line was extracted with $100 \mu \mathrm{l}$ of Cell Extraction buffer (Life Technologies) containing $10 \mathrm{mM}$ Tris, $\mathrm{pH} 7.4 ; 100 \mathrm{mM} \mathrm{NaCl} ; 1 \mathrm{mM}$ EDTA; $1 \mathrm{mM}$ EGTA; $1 \mathrm{mM} \mathrm{NaF} ; 20 \mathrm{mM} \mathrm{Na} \mathrm{P}_{2} \mathrm{O}_{7} ; 2 \mathrm{mM} \mathrm{Na} \mathrm{VO}_{4} ; 1 \%$ Triton X-100; $10 \%$ glycerol; $0.1 \%$ SDS; and $0.5 \%$ deoxycholate. The cell extraction buffer was supplemented with $1 \mathrm{mM}$ PMSF and protease inhibitor cocktail (Roche Diagnostics Corporation, Indianapolis, IN, USA) following manufacturer specifications. The pellets were discarded and $10 \mu \mathrm{l}$ of supernatant from each sample was used for subsequent western blot analyses following our published protocol (17). Primary 

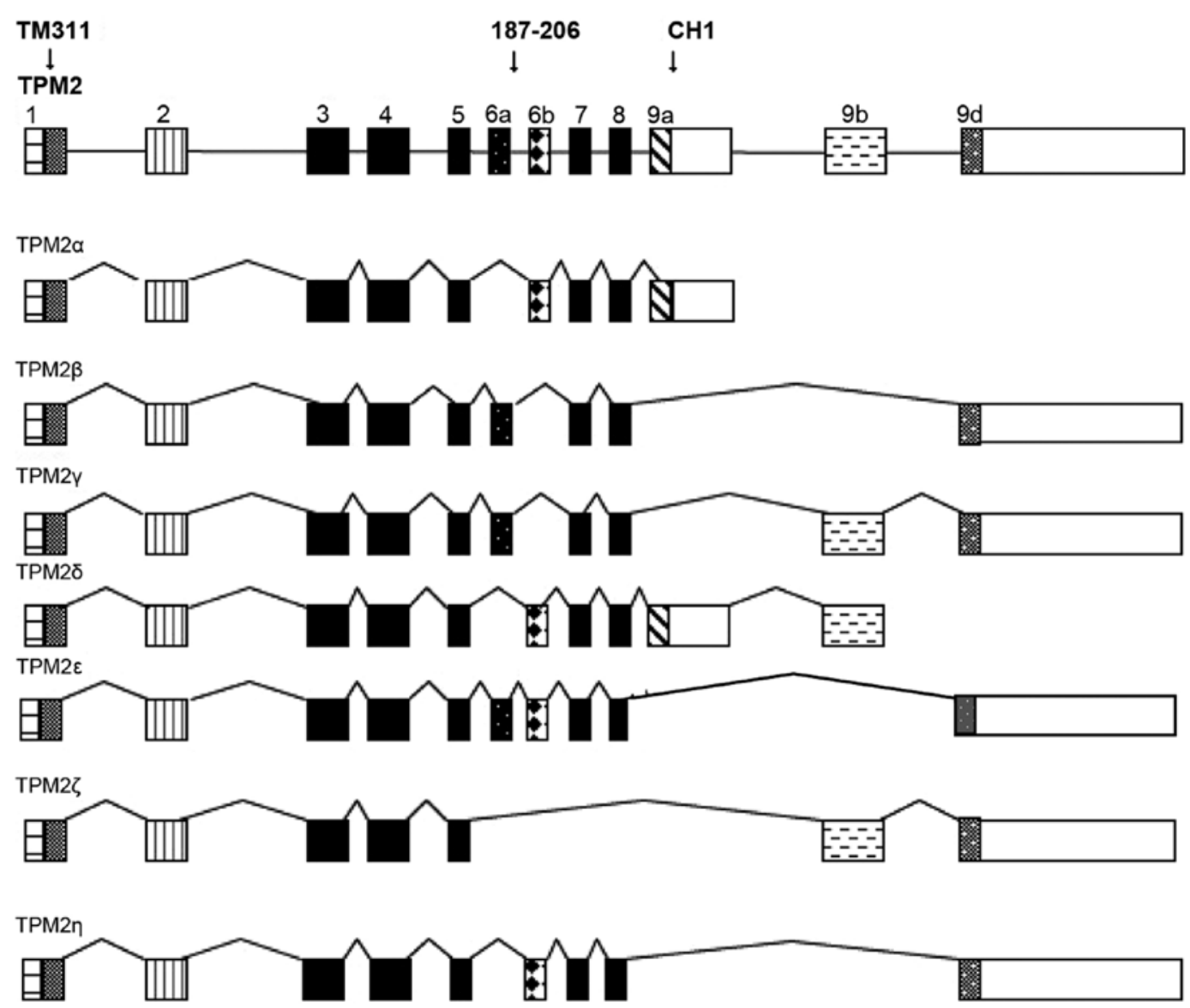

Figure 1. The various exons (boxes) and introns (lines) of the human tropomyosin 2 gene and its various RNA isoforms identified to date. The exons identified by the antibodies TM311, which goes against all four TPM genes, 187-200, which is TPM2-specific, and CH1, which goes against the TPM1, 2 and 3 genes, are identified. TPM1E2 $\alpha$ is not shown because it goes against only the TPM1 gene. Those exons that are translated as peptides are indicated by solid or hatched, markings, while those that are not, are left blank.

Table II. Stress fiber formation in human breast malignant and non-malignant cell lines.

Cell line

Stress fiber formation

\section{Breast cancer

HCC-1143
HCC-1187
BT-474
mDAMB-157
HCC-1806
HCC-1419
mDAMB-453
mDAMB-468
MCF 7

MCF-10 (normal breast)

MCF-12A (normal breast)

MCF-184 B5 (normal breast)

HCC-1143 (BL)

HCC-1187 (BL)
University of Iowa, IA, USA), and TPM2b 187-206 (kind gift of G.L. Prasad, Department of General Surgery and Cancer Biology, Wake Forest University School of Medicine). Secondary antibodies were goat anti-rabbit immunoglobulin HRP and sheep anti-mouse immunoglobulin HRP (GE Healthcare Bio-Sciences, Pittsburgh, PA, USA). Results were scored as negative or + to ++++ . Peptides encoded by TPM2 RNA exons identified by the above antibodies are shown in Fig. 1.

The correlation coefficients (r) between TPM1 $1 \delta$ RA and TPM1 $\lambda$ RNA, TPM2 RNA and TPM1 $\delta$ or $\lambda$ RNA and between stress fiber formation and TPM1 $\lambda$ RNA, TPM $2 \beta$ RNA, TPM $2 \beta$ protein or TBM $2 \beta$ RNA, plus TPM1 $\delta$ and the inverse of TPM1 $\lambda$ RNA were calculated and plotted using Microsoft Excel. The p-values were calculated using the Pearson's ${ }^{\circledR}$ analysis.

\section{Results}

Stress fibers containing both tropomyosin and actin filaments were identified in the cell lines to varying degrees ranging from negative to ++++ (Fig. 2 and Table II). No new TPM2 gene RNA isoforms were identified. TPM $2 \beta$ was the most frequently expressed TPM2 RNA in the breast epithelial lines (Fig. 3 and Table III). TPM $2 \beta$ expression was ++++ in all of the normal breast cell lines and was the only TPM2 


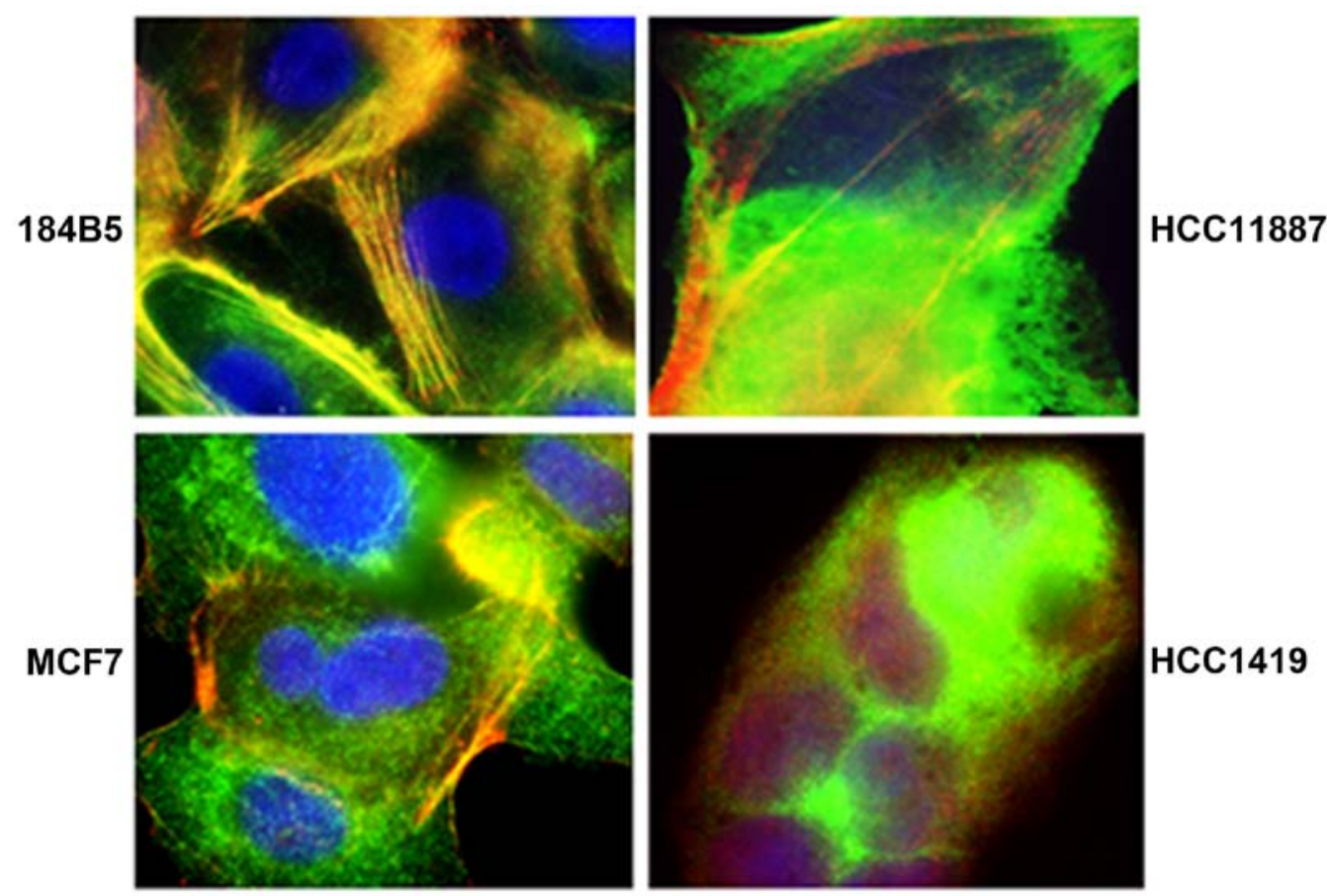

Figure 2. Merged photograph of one 'normal' (184B5) and three malignant (HCC1187, MCF7, and HCC1419) human breast cell lines after staining with TM311, phalloidin and DAPI. The stress fibers are the linear lines that contain both actin and tropomyosin resulting in a variety of colors depending on the background, while the nuclei are stained blue with DAPI. The cell lines were given the following stress fiber scores: $184 \mathrm{~B} 5$ ++++, HCC1187 ++, and MCF7 negative, and HCC1419 negative.

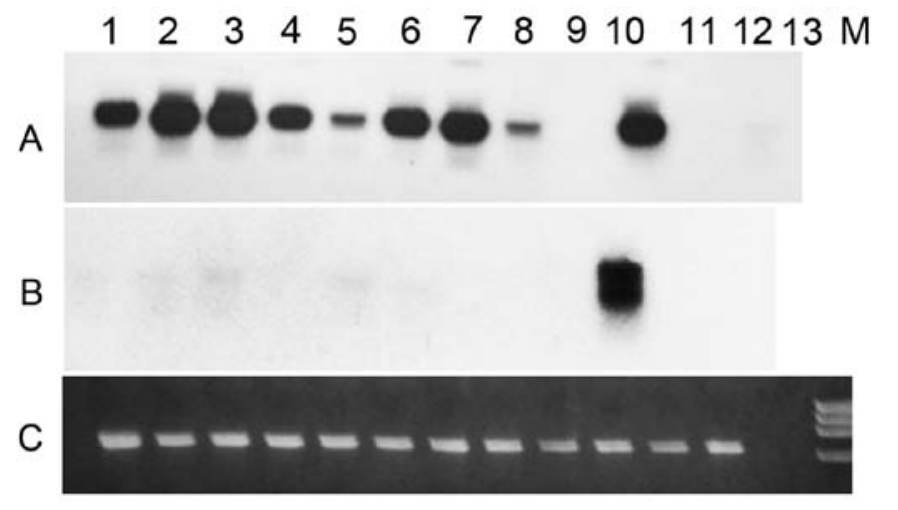

Figure 3. Expression of TPM $2 \alpha$ and TPM $2 \beta$ transcripts in various malignant and non-malignant human breast tumor cell lines. A: Southern hybridization of TPM2 cDNA amplified with TPM2, Exon 1a(+) and TPM2, exon 9d(-) primers, and probed with radio-labeled TPM2 exon 5(+) oligonucleotide probe. B: Southern hybridization of cDNA amplified with TPM2, exon 1a(+) and TPM2, exon 9a(-) and probed with radio labeled TPM2 exon 5(+) oligonucleotide probe. C: Ethidium bromide-stained RT-PCR amplified DNA of human GAPDH. Lane 1, MCF7; lane 2, MCF-10A; lane 3, HCC-1143; lane 4, HCC-1143 BL; lane 5, MDA-MB-453; lane 6, MDA-MB-468; lane 7, HCC-1806; lane 8, HCC-1187; lane 9, BT-474; lane 10, MDA-MB-157; lane 11, HCC-1419; lane 12, HCC-1419 BL; lane 13, primer control.

gene RNA expressed in these cell lines. TPM $2 \beta$ RNA was expressed at varying degrees ranging from negative to ++++ in the malignant breast cell lines. There was high expression of TPM $2 \alpha$ in one of the malignant breast cell lines and minimal expression of TPM $2 \varepsilon$ or TPM $2 \eta$ RNA in a few of the malignant breast epithelial cell lines. There was TPM2 gene RNA expression in one of the B-cell lines and a quite different pattern of expression in the cardiac tissues. Using the four antibodies described, the RNA data and the process of elimination, TPM $2 \beta$ was the only TPM 2 protein expressed in any of the breast cell lines (not shown). Expression was highest in the three normal breast cell lines and was either negative or lower in the malignant breast cell lines (Table IV).

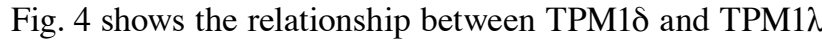
RNA. There was a negative correlation but it was not statistically significant. Similarly there was a non-significant positive correlation between TPM1ठ RNA and TPM $2 \beta$ RNA expression. However, there was a statistically significant, high inverse correlation between TPM $1 \lambda$ RNA and TPM $2 \beta$ RNA expression.

Fig. 5 shows the relationship between stress fiber formation and either TPM $2 \beta$ RNA, TPM $2 \beta$ protein, or TPM $2 \beta$ RNA plus TPM1 $\delta$ RNA plus the inverse of TPM $1 \lambda$ RNA in the 12 malignant and normal breast cell lines. TPM $2 \beta$ RNA and protein expression both had high, statistically significant positive correlations with stress fiber formation. The highest, 
Table III. Tropomyosin 2 gene RNA isoform expression in human breast malignant and non-malignant cell lines.

\begin{tabular}{|c|c|c|c|c|c|c|c|c|}
\hline \multirow[b]{2}{*}{ Cell line } & \multicolumn{8}{|c|}{ RNA isoform expression } \\
\hline & TPM $2 \alpha$ & ТРМ2 $\beta$ & $\mathrm{TPM} 2 \gamma$ & TPM2ठ & TPM $2 \varepsilon$ & 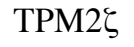 & TPM $2 \eta$ & GAPDH \\
\hline \multicolumn{9}{|l|}{ Breast cancer } \\
\hline HCC-1143 & - & ++++ & - & - & - & - & - & +++++ \\
\hline HCC-1187 & - & + & - & - & - & - & - & +++++ \\
\hline BT-474 & - & - & - & - & - & - & - & +++++ \\
\hline mDAMB-157 & ++++ & +++ & - & - & ++ & - & - & +++++ \\
\hline HCC-1806 & - & +++ & - & - & - & - & - & +++++ \\
\hline HCC-1419 & - & - & - & - & - & - & - & +++++ \\
\hline mDAMB-453 & - & + & - & - & - & - & - & +++++ \\
\hline mDAMB-468 & - & ++ & - & - & + & - & + & +++++ \\
\hline MCF7 & - & ++ & - & - & + & - & - & +++++ \\
\hline MCF-10A (normal breast) & - & ++++ & - & - & - & - & - & +++++ \\
\hline MCF-12A (normal breast) & - & ++++ & - & - & - & - & - & +++++ \\
\hline MCF-184 B5 (normal breast) & - & ++++ & - & - & - & - & - & +++++ \\
\hline HCC-1143 (BL) & - & ++ & - & - & - & - & - & +++++ \\
\hline HCC-1419 (BL) & - & - & - & - & - & - & - & +++++ \\
\hline \multicolumn{9}{|l|}{ Tissue type } \\
\hline Fetal heart & ++ & ++ & - & + & + & + & + & +++++ \\
\hline Adult heart & ++ & +++ & - & + & + & ++ & + & +++++ \\
\hline
\end{tabular}

TPM1ס RNA vs. TPM1 $\lambda$ RNA

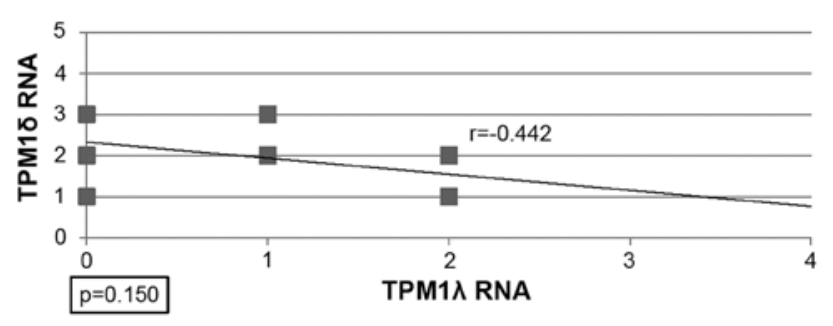

TPM1 $\Lambda$ RNA vs. TPM2 $\beta$ RNA

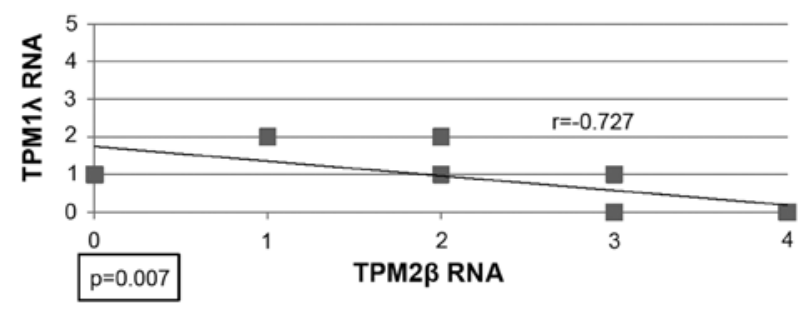

TPM1ס RNA vs. TPM2 $\beta$ RNA

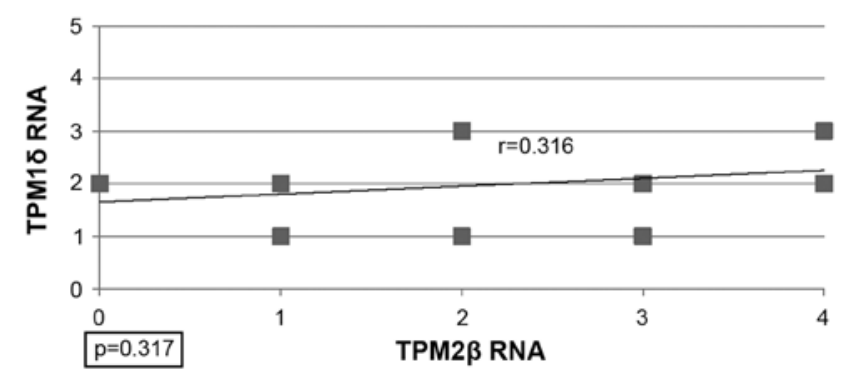

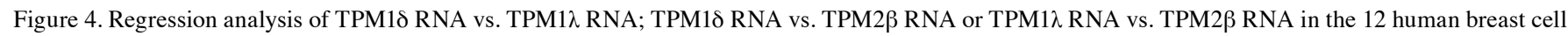
lines. Each box represents one, or more than one cell line. 


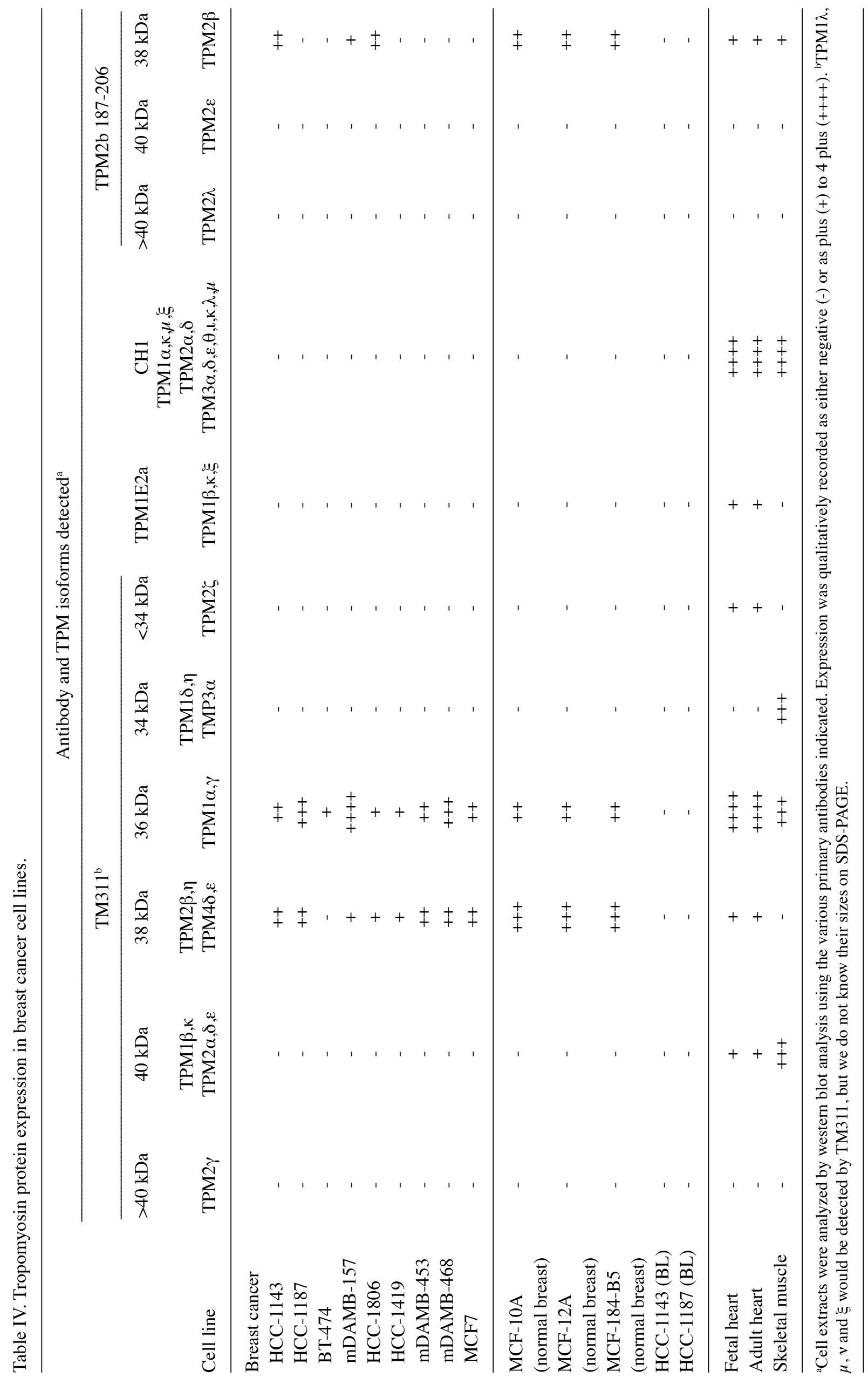


Stress fiber vs. TPM2 $\beta$ RNA

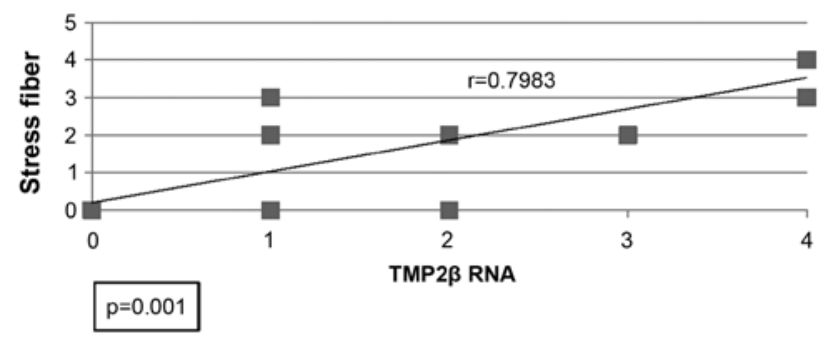

Stress fiber vs. TPM2 $\beta+$ TPM1ס + inverse TPM1 $\lambda$ RNA

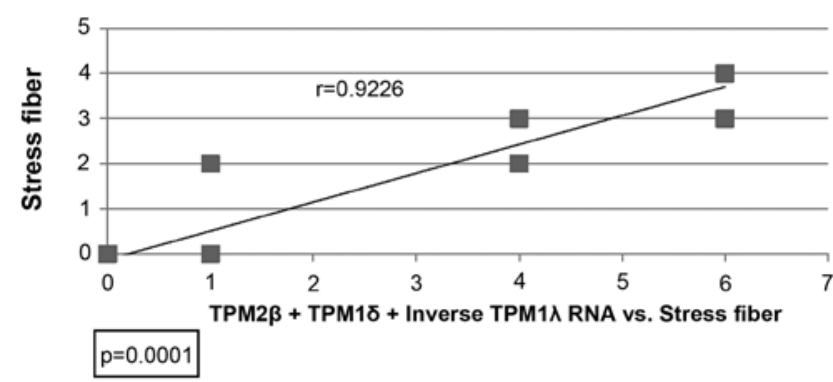

Stress Fiber vs. TPM2 $\beta$ protein

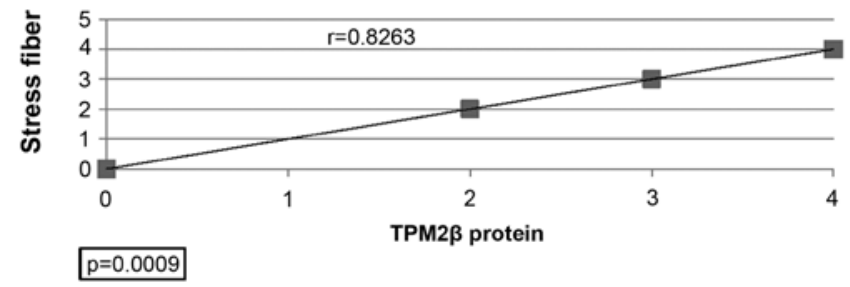

Figure 5. Regression analyses of stress fiber formation vs. expression of TPM2 $\beta$ RNA, TPM2 $\beta$ protein, or TPM2 $\beta$ RNA plus TPM1 $\delta$ RNA plus the inverse of TPM1 $\lambda$ RNA in the 12 human breast cell lines. Each box represents one, or more than one, cell line. Both TPM2 $\beta$ RNA and protein expression had high positive correlations with stress fiber formation (both $\mathrm{p}=0.001)$. The highest correlation with stress fiber formation $(\mathrm{r}=0.92)$ was observed when TPM2 RNA, TPM18 RNA and the inverse of TPM1 $\lambda$ RNA were combined $(\mathrm{p}<0.001)$.

statistically significant, correlation was with the additive value of both TPM2 RNA, TPM18 RNA and the inverse of TPM1 $\lambda$ RNA.

\section{Discussion}

The actin cytoskeleton in epithelial cells contains stress fibers comprised of actin microfilaments and various actin binding proteins (21). They play a major role in anchorage-dependence, cell locomotion, and proliferation. Their dysregulation is considered to play a role in cellular transformation and metastasis $(9,11,22,15)$. Various isoforms of tropomyosin play a critical role in the normal function of these microfilaments and alterations in their expression are believed to be involved in oncogenesis.

The high molecular weight isoforms TPM $1 \gamma$ and $\delta$ and TPM2 $\beta$ have been shown to be expressed in normal human breast epithelial cells and their protein products are incorporated into stress fibers (9). The lower molecular weight isoforms TPM1E and TPM4 $\gamma$ have also been shown to be expressed (9). Downregulation of TPM $1 \gamma$ and $\delta$ and TPM $2 \beta$ isoforms has been observed in some but not all malignant human breast cancer cell lines and primary breast carcinomas $(9,11,22,15)$.
Paradoxically, levels of TPM $2 \beta$ were found to be elevated in primary breast cancers that gave rise to lymph node metastases compared to those that did not (9). TPM2 $\beta$ is considered to protect actin microfilaments from the degradation effects of cofilin (12). TPM2 $\beta$, but not TPM1 $\gamma$, restores the microfilament organization and suppresses malignant growth of a variety of transformed cells including human breast cancer cell lines $(11,22-24)$.

Given the identification and/or prediction of an increasingly greater number of tropomyosin isoforms than known in the past, the sometimes conflicting results mentioned above, and the fact that many reagents used to study tropomyosins are not isoformspecific, we have embarked on a systematic examination of human breast epithelial cell lines for novel isoform expression. Indeed, in a previous publication we detected four novel TPM1 RNA isoforms (16). TPM1 $\lambda$ was the most frequent novel isoform expressed in the malignant breast cell lines and was not found in the three normal breast epithelial cell lines examined. Interestingly, the expression of TPM1 $\lambda$ RNA had a high, statistically significant, inverse correlation with stress fiber formation in the normal and malignant breast cell lines. To date, we do not have a TPM1 $\lambda$-specific reagent or method to identify and quantify TPM1 $\lambda$ protein, but the experiments are in progress. 
In the data reported herein, we did not identify any novel TPM2 isoforms in the breast epithelial cell lines. Of the known TPM 2 isoforms identified in any human tissues, only TPM2 $\beta$ was routinely and robustly expressed at the RNA and protein levels among the breast epithelial cell lines. Its expression inversely correlated with that of TPM1 $\lambda$, suggesting that one may influence the expression of the other or that they share a common regulator with opposite effects. Interestingly, while TPM $2 \beta$ expression had a positive correlation with stress fiber formation, the strongest impact on stress fiber formation was observed when the levels of TPM2 $\beta$ RNA, TPM1 $1 \delta$ RNA and the inverse of TPM1 $\lambda$ RNA were added together. This suggests that their opposite effects could be additive with TPM $1 \lambda$ expression promoting and TPM1 $\delta$ and TPM $2 \beta$ expression suppressing cell transformation.

In conclusion, the discovery and possible biological impact of TPM1 $\lambda$ may explain some of the inconsistent observations regarding TPM1 $\delta$ and TPM $2 \beta$ cited above. Together, TPM1 $\delta$, TPM $1 \lambda$ and TPM2 $\beta$ RNA levels could be considered as a tropomyosin expression index that would very accurately predict stress fiber formation at least in the cell lines studied.

We plan on examining human breast epithelial cell lines for TPM3 and TPM4 expression and developing the techniques and reagents to examine the interactive biology of all of the TPM isoforms in these systems. In order to further delineate the role of tropomyosin expression in the pathogenesis of human breast cancer, these studies will be extended to fresh human tissues as well.

\section{Acknowledgements}

The study was supported by a grant from the Department of Medicine, SUNY Upstate Medical University, Syracuse, New York to Dr J.P. Poiesz.

\section{References}

1. Gunning P, O'Neill G and Hardeman E: Tropomyosin-based regulation of the actin cytoskeleton in time and space. Physiol Rev 88: 1-35, 2008.

2. Lees-Miller JP and Helfman DM: The molecular basis for tropomyosin isoform diversity. BioEssays 13: 429-437, 1991.

3. Perry SV: Vertebrate tropomyosin: Distribution, properties and function. J Muscle Res Cell Motil 22: 5-49, 2001.

4. Pieples K and Wieczorek DF: Tropomyosin 3 increases striated muscle isoform diversity. Biochemistry 39: 8291-8297, 2000.

5. Pittenger MF, Kazzaz JA and Helfman DM: Functional properties of non-muscle tropomyosin isoforms. Curr Opin Cell Biol 6: 96-104, 1994.

6. Wieczorek DF: Regulation of alternatively spliced $\alpha$-tropomyosin gene expression by nerve extract. J Biol Chem 263: 10456-10463, 1988.

7. Dube DK, McLean MD, Zajdel RW, Dube S and Poiesz BJ: Does non-coding RNA play a critical role in sarcomeric tropomyosin expression and subsequent myofibrillogenesis in axolotl heart? J Clin Exp Cardiolog 4: e132, 2013.
8. Dube DK, McLean MD, Dube S and Poiesz BJ: Translational control of tropomyosin expression in vertebrate hearts. Anat Rec (Hoboken) 297: 1585-1595, 2014.

9. Franzén B, Linder S, Uryu K, Alaiya AA, Hirano T, Kato H and Auer G: Expression of tropomyosin isoforms in benign and malignant human breast lesions. Br J Cancer 73: 909-913, 1996.

10. Bharadwaj S and Prasad GL: Tropomyosin-1, a novel suppressor of cellular transformation is downregulated by promoter methylation in cancer cells. Cancer Lett 183: 205-213, 2002.

11. Mahadev K, Raval G, Bharadwaj S, Willingham MC, Lange EM, Vonderhaar B, Salomon D and Prasad GL: Suppression of the transformed phenotype of breast cancer by tropomyosin-1. Exp Cell Res 279: 40-51,2002.

12. Bharadwaj S, Hitchcock-DeGregori S, Thorburn A and Prasad GL: N terminus is essential for tropomyosin functions: $\mathrm{N}$-terminal modification disrupts stress fiber organization and abolishes anti-oncogenic effects of tropomyosin-1. J Biol Chem 279: 14039-14048, 2004.

13. Bakin AV, Safina A, Rinehart C, Daroqui C, Darbary H and Helfman DM: A critical role of tropomyosins in TGF- $\beta$ regulation of the actin cytoskeleton and cell motility in epithelial cells. Mol Biol Cell 15: 4682-4694, 2004.

14. Zhu S, Si ML, Wu H and Mo YY: MicroRNA-21 targets the tumor suppressor gene tropomyosin 1 (TPM1). J Biol Chem 282: 14328-14336, 2007.

15. Helfman DM, Flynn P, Khan P and Saeed A: Tropomyosin as a regulator of cancer-cell transformation. In: Tropomyosin. Gunning P (ed). Springer, Berlin, pp124-131, 2008.

16. Dube S, Yalamanchili S, Lachant J, Abbott L, Benz P, Mitschow C, Dube DK and Poiesz BJ: Expression of tropomyosin 1 gene isoforms in human breast cancer cell lines. Int $\mathrm{J}$ Breast Cancer 2015: 859427, 2015.

17. Dube S, Yalamanchili S, Lachant J, Abbott L, Benz P, Dube DK and Poiesz BJ: Expression of tropomyosin 2 gene isoforms in human cardiac tissue. Int J Cardiol Res 1: 301, 2014.

18. Pinnamaneni S, Dube S, Welch C, Shrestha R, Benz P, Abbott L, Poiesz BJ and Dube DK: Effect of Shz-1, a cardiogenic small molecule, on expression of tropomyosin in axolotl hearts. Am Based Res J 2: 24-40, 2013.

19. Thomas A, Rajan S, Thurston HL, Masineni SN, Dube P, Bose A, Muthu V, Dube S, Wieczorek DF, Poiesz BJ, et al: Expression of a novel tropomyosin isoform in axolotl heart and skeletal muscle. J Cell Biochem 110: 875-881, 2010.

20. Denz CR, Zhang C, Jia P, Du J, Huang X, Dube S, Thomas A, Poiesz BJ and Dube DK: Absence of mutation at the 5'-upstream promoter region of the TPM4 gene from cardiac mutant axolotl (Ambystoma mexicanum). Cardiovasc Toxicol 11: 235-243, 2011.

21. Tojkander S, Gateva G and Lappalainen P: Actin stress fibers - assembly, dynamics and biological roles. J Cell Sci 125: 1855-1864, 2012.

22. Prasad GL, Fuldner RA and Cooper HL: Expression of transduced tropomyosin $1 \mathrm{cDNA}$ suppresses neoplastic growth of cells transformed by the ras oncogene. Proc Natl Acad Sci USA 90: 7039-7043, 1993.

23. Braverman RH, Cooper HL, Lee HS and Prasad GL: Anti-oncogenic effects of tropomyosin: Isoform specificity and importance of protein coding sequences. Oncogene 13: 537-545, 1996.

24. Prasad GL, Masuelli L, Raj MH and Harindranath N: Suppression of src-induced transformed phenotype by expression of tropomyosin-1. Oncogene 18: 2027-2031, 1999. 